\title{
Educação de adultos: percepções sobre o processo ensino-aprendizagem
}

\section{Percepções de adultos sobre ensino-aprendizagem}

\author{
Poliana da Silva Almeida Santos Camargo \\ Selma de Cássia Martinelli
}

\begin{abstract}
Resumo
Esse trabalho teve por objetivo investigar as percepções de alunos na Educação de Jovens e Adultos (EJA) a respeito do processo de ensinoaprendizagem. Foram entrevistados 50 estudantes, 20 do sexo masculino (40\%) e 30 do feminino (60\%), com idades entre 14 e 80 anos, que freqüentavam escolas de ensino fundamental ( $I^{\mathrm{a}}$. a $4^{\mathrm{a}}$. séries) de uma cidade do interior do estado de São Paulo. Uma entrevista semi-estruturada foi realizada, composta por dois eixos principais - aspectos pessoais do aluno e do professor e aspectos relativos ao processo de ensino-aprendizagem. Os resultados revelaram a relação professor-aluno assumida por um papel de destaque nesta modalidade de ensino. $O$ desempenho do aluno é atribuído ao seu esforço ou à vontade de aprender. A escola, de maneira geral, possibilita o aprendizado de habilidades que são consideradas essenciais ao exercício de funções básicas do dia-a-dia, permitindo o resgate da auto- estima dos participantes.
\end{abstract}

Palavras-chave: Educação; Percepções; Ensino-aprendizagem.

\section{Adult education:perceptions about the teaching-learning process}

\begin{abstract}
The objective of this research was to investigate the perception of adult students' on its process of teach-learning. 50 students had been interviewed, 20 males (40\%) and 30 females $(60 \%)$, with ages between 14 to 80 years, that frequented the $I^{\mathrm{a}}$ to $4^{\mathrm{a}}$ Grades of schools of a city from the State of São Paulo. The questionnaire had two main axles - personal aspects of the student and the teacher and relative aspects to the teach-learning process. The results had showed that the teacher-student relationship assumes a role of prominence in this modality of education. The performance of the student is attributed to its effort or will to learn. The school, in a generalized manner, makes possible the learning of abilities that are considered essential to the exercise of basic functions day to day, allowing the rescue of self-esteem among the participants.
\end{abstract}

Key-words: Education; Perceptions; Teach-learning.

\section{Educación de adultos: percepciones sobre el proceso enseñanza-aprendizaje}

\section{Resumen}

Este trabajo tuvo por objetivo investigar las percepciones de alumnos de la educación de jóvenes y adultos - EJA sobre su proceso de enseñanzaaprendizaje. Fueron entrevistados 50 estudiantes, 20 del sexo masculino (40\%) y 30 del femenino (60\%), con edades entre 14 y 80 años, que frecuentaban del $I^{\circ}$ al $4^{\circ}$ grado de la enseñanza primaria de escuelas de una ciudad del interior del Estado de São Paulo. Fue realizada una entrevista semiestructurada compuesta por dos ejes principales - aspectos personales del alumno y del profesor y aspectos referentes al proceso de enseñanzaaprendizaje. Los resultados revelaron que la relación profesor-alumno asume un papel de destaque en esta modalidad de enseñanza. El desempeño del alumno es atribuido a su esfuerzo o ganas de aprender. La escuela, de manera general, permite el aprendizaje de habilidades que son consideradas esenciales para el ejercicio de funciones básicas del día a día, permitiendo el rescate del auto-estima de los participantes.

Palabras-clave: Educación; Percepciones; Enseñanza-Aprendizaje. 


\section{Introdução}

A Educação tem sido apontada como um direito de todo cidadão, no entanto, poucos têm acesso a ela ou permanecem freqüentando as salas de aula. Dados recentes, divulgados pelo Instituto Nacional de Estudos e Pesquisas Educacionais Anísio Teixeira (INEP) e Ministério da Educação - MEC (2004), apontam que em 2004, cerca de 33.889.03I crianças foram matriculadas no ensino fundamental, mas dessas apenas I,56\% conseguem concluir um curso universitário. Essa realidade é ainda mais alarmante se analisarmos o contexto da alfabetização e escolarização de adultos, pois se trata de um contingente de pessoas que, em raras oportunidades, usufruiu seus direitos. Segundo o Instituto Brasileiro de Geografia e Estatística - IBGE (2006), o índice de analfabetos no Brasil era de $11,6 \%$ da população no ano de 2003. Em 1998 a taxa era de $13,8 \%$, ou seja, em 6 anos houve uma diminuição de apenas 2,2\% no percentual de pessoas analfabetas. Segundo o INEP e MEC (2004) o número de matrículas na Educação de Jovens e Adultos (EJA) em 2004 foi de 3.419.675 no ensino fundamental e de I.157.593 no ensino médio.

A análise do percurso histórico da Educação de Jovens e Adultos aponta para o fato de que esta sempre esteve, de certa forma, em segundo plano diante de outros níveis de ensino. No entanto, com as novas tendências de mercado e a necessidade cada vez mais crescente de qualificação profissional, esse nível de ensino tem ganhado ênfase e várias alternativas têm sido propostas.

A decodificação da informação escrita, seja por meio da leitura ou da escrita, tem se tornado uma peça fundamental no que diz respeito à qualificação de mão-de-obra para o mundo do trabalho e uma das ferramentas mais preciosas para se obter poder e riqueza. Dessa forma, aprofundar os conhecimentos na tentativa de entender como os indivíduos adultos analisam os processos de ensinar e aprender e o contexto escolar, entre outras questões, parece oportuno.

Uma análise dos estudos nessa área permitiu verificar que os trabalhos são diversificados e seus autores se preocupam com diferentes aspectos da educação de adultos. Por meio de uma revisão de literatura foi possível o levantamento de 120 trabalhos entre artigos científicos, dissertações, teses e livros publicados no período de 1976 a 2004. Várias pesquisas enfatizaram o estudo das políticas públicas, análises históricas de momentos significativos nessa área, programas, campanhas e projetos no contexto da Educação de Jovens e Adultos, dentre elas as de Manfredi (1976), Marques (1977), Santos (1992b), Silva (1995), Pierro (1996), Machado (1997), Oliveira (1997), Moll (1998), Saraiva (1998), Casério (2003) e Amaral (2003), entre outros.

Questões relacionadas ao ensino da leitura (Nepomuceno, 1990; Araújo 1990; Gervásio, 1995 e Luiz, 2003), escrita (Asmar 1990, Slomp, 1991; Santos 1992b; Sauner, 1994; Nogueira 1995; Simões, 1995; Araújo 1995 e Cossentini, 2002, Gakya e Martinelli, 2005) e matemática (Souza, 1988; Monteiro, 1998; Ferreira, 1998, Toledo, 1998; Abreu, 1999; Danyluk, 200I e Fantinato, 2003), também se destacam entre as pesquisas.

Alguns trabalhos investigaram aspectos do desenvolvimento cognitivo, lingüístico e perceptivo em jovens e adultos (Moraes, 1994; Piconez, 1995) e outros a educação no meio rural e no contexto do movimento dos trabalhadores sem-terra, como os estudos de Neptune (1989) e Souza (1991), Bezerra Neto (1998) e Alvarino (2003), para citar alguns. Souza (1996), Campos (1998), Carvalho (1998) e Silva (1998) investigaram a trajetória política educacional do Movimento de Alfabetização de Jovens e Adultos - MOVA. Estudos que avaliaram as propostas de educação semipresencial e a distância com o uso da tecnologia, também foi objeto de estudo de alguns pesquisadores como Anunciação (1987), Costa (1987), Soares (1987), Burgos (1990), Braga (1996), Pravadelli (1997) e Cordenonssi (1998).

As percepções dos alunos sobre o processo ensino-aprendizagem, interesse de pesquisa deste estudo, também foi investigada por outros pesquisadores. Scomazzon (199I) buscou analisar os significados das representações relativas à escola, educação, sociedade, trabalho e valores sociais (religião, raça, poder/controle, dinheiro) de alunos e de seus professores. Os resultados demonstram que 
a relação com o trabalho é apenas de sobrevivência e não tem vínculo com o prazer. $O$ significado de ser alfabetizado está vinculado à questão da ascensão social, mas principalmente com a auto-estima. O modelo de escola desejada é o da tradicional - cadeiras enfileiradas, professor que sabe e decide tudo, silêncio, acertos e erros - pois é grande a resistência à mudança e o medo dos erros. Os aspectos mais valorizados no professor foram paciência, amizade e atenção bem como a questão da competência sobre o gostar do que faz, saber se comunicar, ser pontual e responsável. No relato dos professores foi possível identificar os conflitos que permeiam a prática pedagógica. Com relação à evasão dos alunos, os professores apontaram como prováveis causas, o trabalho, família, problemas de adaptação, doença, mudança de endereço, transporte, envolvimento com drogas e falta de segurança.

Sachetti (1992), por sua vez, objetivou descrever e analisar as concepções e expectativas de alunos adultos analfabetos, sobre o desempenho do professor. Concluiu que tanto os alunos quanto os professores têm uma visão estereotipada dos papéis de cada um. Na visão do professor, a incapacidade, as deficiências internas e as dificuldades de aprendizagem dos alunos interferem no trabalho docente, comprometendo a eficiência do mesmo. $\mathrm{Na}$ visão dos alunos, o professor é aquele que deve deter todo o conhecimento.

Cruz (1993) entrevistou alunos adultos em processo de alfabetização e investigou o significado do ensino considerado eficaz e a representatividade da figura do professor nesse processo. Os resultados demonstraram a importância da figura do professor nas situações de fracasso ou sucesso na alfabetização, apontando que a qualidade do trabalho desenvolvido pelo professor é favorecida pela afetividade, eficácia profissional e interesse em partilhar com os alunos. Os alunos relataram procurar a escola por acreditar que ela fornecerá um conhecimento básico, possibilitará o domínio da leitura e da escrita, e, conseqüentemente, dará oportunidade a uma melhor compreensão do mundo.

Tratar do fenômeno da evasão ou do abandono escolar e a percepção da escola, sob o ponto de vista dos alunos evadidos que regressam à escola para completar seus estudos, foi o objetivo do estudo de Foltran (1993). Entre os vários motivos elencados pelos participantes para retornarem aos bancos escolares está o desejo de uma vida melhor, o sonho de ser alguém, a possibilidade de conquistar melhores postos de trabalho, competência para ajudar os filhos que estão na escola, ler e escrever melhor. Os alunos relataram que a escola que freqüentam hoje dá oportunidades para exposição de suas idéias, conhecimento das idéias dos colegas, ajuda no desenvolvimento crítico e capacita profissionalmente.

O objetivo do trabalho de Souza (1994) foi compreender os sentimentos, as expectativas com relação à escola e as representações dos alunos dos cursos de alfabetização e pós-alfabetização de jovens e adultos (EJA) que tiveram passagem pelo ensino regular. A autora fez um resgate da história de vida de 04 alunos, com idades entre 14 e 18 anos, para saber o que eles pensavam e sentiam a respeito de suas experiências vividas e como eles a reconstruíam por meio da memória. A entrevista abordou questões referentes aos dados pessoais, à família, ao trabalho, ao lazer, aos acontecimentos relacionados à infânciaadolescência-família e escolaridade. Os resultados demonstraram que os alunos têm responsabilidade, trabalham para ajudar no sustento e suprir as necessidades básicas da família. Esses são alguns dos motivos que justificaram a não-permanência deles na escola quando eram crianças. Os problemas enfrentados no âmbito educacional, tais como reprovações, dificuldades no desempenho e dificuldades nas relações interpessoais, também contribuíram para as evasões escolares. No entanto, depois de vivenciarem um tempo longe da escola e retornarem, percebem que o valor dado a ela vai se fortalecendo e apontam para o fato da escola ser algo essencial para suas vidas e um meio para a ascensão social.

Com o objetivo de compreender o significado do retorno à escola, na constituição da identidade e na construção dos projetos de vida, Oliveira (1996) investigou os processos de alfabetização de adolescentes e adultos de ambos os sexos, com idade entre 15 e 65 anos. Evidenciou-se que o retorno à 
escola significa um marco decisivo no restabelecimento dos seus vínculos com o conhecimento escolar, libertando-os do estigma do analfabetismo e dos sentimentos de inferioridade.

Santana (1996) objetivou verificar as estratégias utilizadas por analfabetos e recém-alfabetizados para suprir seu analfabetismo e identificar as imagens que têm de si mesmos. A autora conclui que os alunos buscam a escolarização tentando responder às exigências impostas pelo mundo letrado. Acreditam que ao dominar as habilidades de ler e escrever, eles poderão conquistar a independência facilitando as necessidades ligadas à sobrevivência. Fátima (1997), por sua vez, analisou as expectativas sócioeducacionais de alfabetizandos jovens e adultos e concluiu que os alfabetizandos buscam a superação das dificuldades diárias por meio da escolarização e procuram um curso de alfabetização para atender às exigências sociais, econômicas, políticas e culturais da sociedade. Afirmam que, depois que passaram a freqüentar o curso de alfabetização suas vidas melhoraram pois aprenderam a ler e escrever, eles se comunicam melhor, aumentaram sua auto-estima, resolveram com mais facilidade os problemas do cotidiano, melhoraram o desempenho profissional e a visão da vida e do mundo.

Tavares (1999) preocupou-se em identificar e analisar os significados atribuídos à escolarização por alunos da Educação de Jovens e Adultos com destaque à aquisição da leitura e escrita. As análises revelaram que os alunos têm consciência de que suas aprendizagens são significativas embora não atinjam as exigências complexas envolvidas na leitura e escrita. Por outro lado, Almeida (2003) realizou uma pesquisa com alunos adultos, de um curso de alfabetização, com o objetivo de descobrir quais são os desejos e necessidades dessas pessoas. Dentre as necessidades mais relevantes, encontram-se a de registrar cálculos mentais para conquistar credibilidade, ajudar os filhos na realização das tarefas, ler a bíblia, obter um diploma e realizar compras. Em relação às dificuldades, o preenchimento de ficha de seleção para emprego, a leitura de manuais que circulam no ambiente de trabalho, a ausência de óculos ou o desconhecimento de algumas letras e a escolaridade insuficiente foram citados. Quanto às estratégias utilizadas para minimizar suas dificuldades, a leitura lenta, a antecipação de significados, a utilização da comunicação oral foram elencadas como também o aguçar da memorização e a comparação de símbolos.

Com o intuito de verificar os elementos facilitadores/motivadores e dificultadores durante a entrada e a permanência no curso de alfabetização de adultos, Santos (2003) encontrou que entre os elementos facilitadores/motivadores destacaram-se a possibilidade de passar em exames de seleção, o acesso ao ambiente universitário, a proposta pedagógica que valoriza as experiências de vida, o resgate do desejo de aprender, a gratuidade dos estudos, o material didático e a alimentação fornecida pelo projeto como também o carinho, atenção e respeito dos professores.

Fernandes (2004) analisou as representações sociais de alunos e professores sobre as significações da alfabetização, as representações acerca do analfabeto/alfabetizando adulto e as representações acerca do alfabetizador de adultos. Concluiu que os alunos vêem o processo de alfabetização como algo muito significativo e um meio para se chegar a melhores condições de vida e de trabalho. As representações sociais dos alfabetizandos sobre o analfabeto foram muito negativas. A representação positiva sobre a figura do professor esteve diretamente ligada à atenção e aos tratamentos carinhosos direcionados aos alunos. Por sua vez, os professores também manifestaram uma visão negativa e uma baixa expectativa sobre o analfabeto. Também revelaram uma perspectiva positiva sobre a função do professor, embora tenham consciência da desvalorização e desprestígio social da profissão.

Pode-se constatar que os trabalhos realizados com o objetivo de investigar as percepções dos jovens e adultos sobre o processo de alfabetização e escolarização não são muitos e a marca destes estudos está no fato de terem sido realizados com um número reduzido de participantes, relativos a uma experiência ou a um contexto específico de algumas regiões do país. Os estudos, em sua maioria, não estão publicados em periódicos de divulgação nacional, encontram-se em teses e dissertações, o que dificulta muito o acesso 
a esse material e prejudica $\circ$ avanço das pesquisas e da divulgação dos estudos nessa área.

Dessa forma, o objetivo deste trabalho é conhecer algumas dimensões do processo de escolarização de alunos jovens e adultos no que se refere à sua aprendizagem e sua relação com o educador e a escola e o desempenho e metodologia do professor.

\section{Método}

\section{Participantes}

Os participantes da pesquisa foram escolhidos por conveniência, de acordo com o interesse e o consentimento dos mesmos em fazer parte deste trabalho. Foram entrevistadas 50 estudantes de ambos os sexos, que freqüentavam as classes de $\mathrm{I}^{\mathrm{a}}$. a $4^{\mathrm{a}}$. séries do Ensino Fundamental da Educação de Jovens e Adultos, da cidade de Bauru/SP. A faixa etária dos participantes variou de 14 a 80 anos, sendo 20 pessoas do sexo masculino e 30 do sexo feminino. As entrevistas foram realizadas com 13 alunos da $I^{a}$. série; 12 alunos da $2^{\mathrm{a}}$. série; II alunos da $3^{\mathrm{a}}$. série $\mathrm{e}$ 14 alunos da $4^{\text {a }}$. série.

\section{Material}

Os trabalhos realizados por Sachetti (1992), Souza (1994), Montero (1996) e José e Coelho (1999) subsidiaram a elaboração de 07 questões que se referiam ao perfil do professor e aluno (3 questões) e ao processo ensino-aprendizagem (4 questões). Essas nortearam a realização de uma entrevista semiestruturada com os participantes.

\section{Procedimento}

Após a elaboração do questionário e a realização do estudo-piloto, foi realizado um contato com a Secretaria de Educação de uma cidade do interior do Estado de São Paulo a fim de se obter autorização para a realização da pesquisa. $O$ Centro de Educação de Jovens e Adultos (CEJA) conta com 56 classes distribuídas pela cidade. Dentre essas, foi escolhida I instituição de cada região da cidade, num total de 04 classes, abarcando pessoas de 17 bairros. As entrevistas, realizadas por meio de um questionário, foram feitas individualmente, com duração de Ih30min, no pátio das instituições de ensino pela própria pesquisadora que registrou as respostas.

\section{Resultados}

Os dados foram analisados à luz da análise de conteúdo, seguindo as orientações de Bardin (1977) e Richardson, Correia, Peres e Wanderley, (1989). Este procedimento divide-se em três fases, denominadas pré-análise, análise do material e tratamento dos resultados. Na pré-análise procedese a uma leitura flutuante, estabelecendo os procedimentos de análise. A segunda fase consiste na codificação, categorização e quantificação das informações coletadas. $O$ tratamento dos resultados é a terceira e última fase desse processo e implicam na inferência e interpretação dos conteúdos já categorizados, buscando, em nosso caso específico, as percepções dos alunos entrevistados sobre o processo de ensino-aprendizagem.

Os resultados estão organizados em dois blocos de dados. O primeiro refere-se ao perfil de professor e aluno, tais como visto pelos participantes do estudo. O segundo bloco de dados trata de aspectos relativos ao processo ensino-aprendizagem no que diz respeito às dificuldades encontradas pelos alunos, desempenho enquanto alunos, atividades e matérias vistas na escola.

\section{Perfil de professor e alunos da EJA}

Com relação ao perfil do professor da EJA, os alunos foram unânimes em afirmar que todos os professores que ministravam aulas para eles eram bons. Podemos verificar, na Tabela I, que os indicativos do bom ou mau professor estão mais vinculados ao aspecto afetivo do que à competência do professor.

Para os entrevistados, ser um bom professor está muito relacionado aos aspectos de ordem afetiva $(61,73 \%)$ uma vez que afirmam que o bom professor é aquele que é atencioso, paciente, educado, carinhoso, alegre dentre outras características. Os aspectos metodológicos ocuparam o segundo lugar $(37,04 \%)$ na fala dos participantes, enquanto o aspecto intelectual fica em último plano (1,23\%). As 
Tabela I - Estatísticas descritivas das características do bom e mau professor

\begin{tabular}{|c|c|c|c|c|}
\hline \multirow[b]{2}{*}{ Características } & \multicolumn{2}{|c|}{ Bom professor } & \multicolumn{2}{|c|}{ Mau professor } \\
\hline & $\begin{array}{l}\text { Freqüência } \\
\text { de respostas }\end{array}$ & $\begin{array}{c}\text { Porcentagem } \\
\%\end{array}$ & $\begin{array}{l}\text { Freqüência } \\
\text { de respostas }\end{array}$ & $\begin{array}{c}\text { Porcentagem } \\
\%\end{array}$ \\
\hline Aspectos afetivos & 50 & $61,73 \%$ & 18 & $60,00 \%$ \\
\hline Aspectos metodológicos & 30 & $37,04 \%$ & 10 & $33,33 \%$ \\
\hline Aspectos intelectuais & 01 & $1,23 \%$ & 02 & $6,67 \%$ \\
\hline Total & 81 & $100,00 \%$ & 30 & $100,00 \%$ \\
\hline
\end{tabular}

características do mau professor, por sua vez, seguem a mesma ordem de importância. Os aspectos afetivos (60\%) correspondem a comportamentos como gritar, maltratar, ficar de mau humor, não dar atenção e dentre outros. Com relação aos aspectos metodológicos $(33,33 \%)$ surgiram observações como largar os alunos, falar muito, ficar conversando no momento em que os alunos estão resolvendo exercícios, dentre outros. Os aspectos intelectuais aparecem em último lugar nas respostas dos participantes $(6,67 \%)$.

$\mathrm{Na}$ Tabela 2 são apresentadas as características do bom aluno, apontadas pelos entrevistados.

Alguns alunos hesitaram, num primeiro momento, em responder à questão referente às características de um bom aluno e a tecer considerações sobre si mesmos por acreditarem que somente a professora poderia fazer esse julgamento. Dos participantes que responderam pode-se notar que as principais características apontadas estão relacionadas aos aspectos comportamentais como: ter respeito, fazer silêncio e ter bom comportamento $(65,75 \%)$. As características vinculadas ao esforço aparecem em segundo lugar (26,03\%). Alguns participantes $(5,48 \%)$ se recusaram a responder. $O$ perfil do bom aluno, para alguns dos entrevistados, ainda está muito vinculado ao aluno quieto, que não faz perguntas, que não levanta de sua carteira, que não conversa com a professora sobre os seus problemas e que gosta de tudo sem questionar $(2,74 \%)$.

\section{Aspectos do Processo Ensino-Aprendizagem}

Os motivos elencados pelos alunos sobre o bom desempenho na escola estão elencados na Tabela 3.

Os entrevistados atribuíram como principais indicadores de seu bom desempenho o próprio esforço, vinculado principalmente à vontade de aprender $(25,92 \%)$ e ao fato de já possuir as competências necessárias para aprender tais como aprender rápido e ser inteligente (16,67\%). É interessante observar que alguns acreditam que o bom desempenho está vinculado a algo externo a eles apoio da família, dedicação da professora, exigência dos pais e a até mesmo a providência divina $(7,41 \%)$. No entanto, $50 \%$ dos alunos não responderam a essa pergunta.

Quanto às dificuldades de aprendizagem mais freqüentes apontadas pelos alunos, a Tabela 4 apresenta as principais em ordem decrescente na fala dos participantes.

Tabela 2 - Estatísticas descritivas das características do bom aluno

\begin{tabular}{|c|c|c|}
\hline Características & Freqüência de respostas & Porcentagem \\
\hline Aspectos comportamentais & 48 & $65,75 \%$ \\
\hline Esforço & 19 & $26,03 \%$ \\
\hline Somente a professora pode responder & 04 & $5,48 \%$ \\
\hline Outros & 02 & $2,74 \%$ \\
\hline Total & 73 & $100,00 \%$ \\
\hline
\end{tabular}


Tabela 3 - Estatística descritiva dos aspectos atribuídos ao seu bom desempenho como aluno

\begin{tabular}{lcc}
\hline \multicolumn{1}{c}{ Motivos } & Freqüência de respostas & Porcentagem \\
\hline Esforço próprio & 14 & $25,92 \%$ \\
Competência ou capacidade & 09 & $16,67 \%$ \\
Atribuições externas & 04 & $7,41 \%$ \\
Não respondeu & 27 & $50,00 \%$ \\
\hline \multicolumn{1}{c}{ Total } & 54 & $100,00 \%$ \\
\hline
\end{tabular}

Tabela 4 - Estatísticas descritivas das dificuldades escolares

\begin{tabular}{lcc}
\hline \multicolumn{1}{c}{ Dificuldades } & Freqüencia de repostas & Porcentagem \\
\hline Leitura & 19 & $20,43 \%$ \\
Escrever corretamente & 16 & $17,20 \%$ \\
Atividades matemáticas & 12 & $12,90 \%$ \\
Problemas individuais & 09 & $9,68 \%$ \\
Freqüenta a escola a pouco tempo & 05 & $5,38 \%$ \\
Problemas familiares & 03 & $3,22 \%$ \\
Não respondeu & 29 & $31,18 \%$ \\
\hline \multicolumn{1}{c}{ Total } & 93 & $100,00 \%$ \\
\hline
\end{tabular}

Observa-se que as dificuldades escolares estão relacionadas principalmente com a leitura $(20,43 \%)$, com a escrita correta - pontuação, acentos, vírgulas, agrupamento e separação de sílabas e letras (I7,20\%), às atividades matemáticas - contas, expressões numéricas, tabuadas, confusão entre os números, sinais $(12,90 \%)$ e a problemas individuais de várias ordens tais como: estudar sozinho, idade avançada, nunca ter freqüentado a escola, problemas de vista, falta de tempo para estudar em casa, locomoção até escola, dentre outros $(9,68 \%)$. Alguns participantes da pesquisa preferiram não responder essa questão (31,18\%).

As atividades que os alunos mais e menos gostam de realizar em sala de aula estão apresentadas na Tabela 5 .

Tabela 5 - Estatísticas descritivas das atividades acadêmicas preferidas pelo estudante na escola

\begin{tabular}{lcccccc}
\hline \multirow{2}{*}{ Atividade } & \multicolumn{2}{c}{ Mais gosta } & & \multicolumn{2}{c}{ Menos gosta } \\
\cline { 2 - 3 } \cline { 6 - 7 } & $\begin{array}{c}\text { Freqüência } \\
\text { de respostas }\end{array}$ & $\begin{array}{c}\text { Porcentagem } \\
\%\end{array}$ & & $\begin{array}{c}\text { Freqüência de } \\
\text { respostas }\end{array}$ & $\begin{array}{c}\text { Porcentagem } \\
\%\end{array}$ \\
\hline Atividades de escrita & 24 & $30,38 \%$ & & 13 & $28,89 \%$ \\
Atividades matemáticas & 19 & $24,05 \%$ & & 19 & $42,22 \%$ \\
Atividades de leitura & 14 & $17,72 \%$ & & 07 & $15,55 \%$ \\
Atividades de desenho e & 04 & $5,06 \%$ & & 01 & $2,22 \%$ \\
pintura & - & - & & 05 & $11,12 \%$ \\
Não responderam & 18 & $22,79 \%$ & & - & - \\
Todas as atividades & 79 & $100,00 \%$ & & 45 & $100,00 \%$ \\
\hline Total & & & & & &
\end{tabular}


Verificou-se que as atividades citadas são diversificadas. Aquelas que os alunos mais gostam de executar são as atividades de escrita, que aparecem em primeiro lugar $(30,38 \%)$, as atividades matemáticas, principalmente, as contas de adição e subtração ocupam o segundo lugar $(24,05 \%)$ e as atividades de leitura, o terceiro lugar (I7,72\%). Muitos afirmam ainda que gostam de todas as atividades $(22,79 \%)$ propostas pela professora. As atividades que os entrevistados menos gostam são as de matemática, destacando as contas de multiplicação e divisão (42,22\%). Num segundo momento, aparecem as atividades de escrita como formar palavras e frases $(28,89 \%)$ e em terceiro lugar as atividades de leitura, principalmente a atividade de interpretação de textos $(6,67 \%)$. Podemos verificar, por meio dos relatos, que as atividades que exigem mais, no que diz respeito à reflexão e cálculo mais complexos, são aquelas que os alunos não gostam tanto. As atividades de desenho e pintura são pouco citadas. Outros afirmam que todos os trabalhos da escola são importantes, por isso precisam gostar de tudo (22,79\%).

As disciplinas que os alunos mais e menos gostam estão elencadas na Tabela 6.

Observamos que as disciplinas que os alunos mais gostam são Matemática (46\%), Língua Portuguesa (36\%) e História (12\%) e aquelas que eles menos gostam são Matemática $(55,17 \%)$ e Língua Portuguesa $(20,67 \%)$. Podemos verificar que as disciplinas de Matemática e Língua Portuguesa são as preferidas por alguns alunos e também as menos queridas por outros.
Muitos entrevistados também respondem que não existe a que eles menos gostem $(52,63 \%)$ ou que gostam de todas $(31,58 \%)$, enquanto $15,79 \%$ dos entrevistados disseram não saber responder à questão.

\section{Discussão}

A análise da percepção dos alunos jovens e adultos sobre o processo de ensino-aprendizagem contribui para $\circ$ processo investigativo de conhecimento da realidade dessa modalidade de ensino. Este estudo se consubstanciou como uma tentativa de apreensão das representações desses alunos a respeito de si mesmos, da escola, dos professores e do processo ensinoaprendizagem e alguns pontos serão discutidos a seguir.

A questão da afetividade, no contexto da Educação de Jovens e Adultos, principalmente na relação professor-aluno, foi um dos elementos que se destacou. É possível observar que as características do professor, atribuídas pelos entrevistados, estão estreitamente vinculadas ao aspecto afetivo. Relatam que o bom professor é aquele que ensina bem, mas que é antes de qualquer coisa, atencioso e educado. Estudos como o de Scomazzon (199I), Cruz (1993) e Fernandes (2004) também apontaram para o fato de que, a representação positiva sobre a figura do professor está intrinsecamente ligada à atenção, ao respeito e ao tratamento carinhoso destinado aos

Tabela 6 - Estatísticas descritivas da avaliação das disciplinas pelos estudantes

\begin{tabular}{|c|c|c|c|c|}
\hline \multirow[b]{2}{*}{ Disciplinas } & \multicolumn{2}{|c|}{ Mais gosta } & \multicolumn{2}{|c|}{ Menos gosta } \\
\hline & $\begin{array}{l}\text { Freqüência } \\
\text { de respostas }\end{array}$ & $\begin{array}{c}\text { Porcentagem } \\
\%\end{array}$ & $\begin{array}{l}\text { Freqüência de } \\
\text { respostas }\end{array}$ & $\begin{array}{c}\text { Porcentagem } \\
\%\end{array}$ \\
\hline Matemática & 23 & $46,0 \%$ & 16 & $55,17 \%$ \\
\hline Língua Portuguesa & 18 & $36,0 \%$ & 06 & $20,69 \%$ \\
\hline História & 06 & $12,0 \%$ & 04 & $13,80 \%$ \\
\hline Educação Artística & 01 & $2,0 \%$ & 02 & $6,90 \%$ \\
\hline Geografia & 01 & $2,0 \%$ & 01 & $3,44 \%$ \\
\hline Ciências & 01 & $2,0 \%$ & - & - \\
\hline Total & 50 & $100,0 \%$ & 29 & $100,00 \%$ \\
\hline
\end{tabular}


alunos. Entre os participantes deste estudo, este elemento também foi primordial e podemos verificar este fato em suas falas, como se apresenta a seguir.

"Ele tem que sê humilde, tem que entendê a nossa situação, que véio é difícil, tem que tê paciência". (A.F., 50 anos, sexo feminino, $I^{a}$. série, do lar) ${ }^{\prime}$

"Vai dependê da gente. Tem que respeitá o professor. A gente tem que tê educação com o professor, porque ele quebra muito a cabeça com a gente. A gente que vai fazê o professor". (C.N.S., 23 anos, sexo feminino, $4^{\mathrm{a}}$. série, doméstica)

"Ele tem que ensiná bem, tem que tê um bom estudo". (J.T.A., 45 anos, sexo feminino, $2^{\mathrm{a}}$. série, do lar)

Outro fato significativo, extraído por meio das falas dos alunos é que estes devem respeitar o professor porque é a pessoa que os "agüenta", que "tem paciência" e que "sabe tudo". No estudo de Sachetti (I992) também ficou evidente, na opinião dos alunos, que o professor é aquele que detém o conhecimento, sendo esta uma expectativa por parte dos mesmos.

Outro fato a se destacar na fala dos participantes, quando questionados sobre a qualidade das aulas que estão sendo ministradas pelos professores da EJA, foi apontarem para o fato de que "tudo está bom" ou "ótimo". Percebemos uma certa dificuldade dos entrevistados em separar o aspecto profissional do aspecto pessoal presente na figura do professor, pois ser boa pessoa, é diferente de ser bom profissional. Alguns alunos compararam a professora como alguém da família ou como sendo sua mãe; aquela para quem eles contam seus problemas e pedem conselhos sobre todos os assuntos:

"A professora me deu a maior força, é muito atenciosa. A professora é um amor, tem muita paciência. É uma pessoa meiga, amiga. Como professora, ela é 100. Professora é como uma segunda mãe. Aquilo que sua mãe não pode te ensinar, você aprende com a professora". (A.C., 40 anos, sexo masculino, $4^{\mathrm{a}}$. série, motorista)

"Tenho a professora como alguém da família. Ela caiu do céu". (L.F.B., 43 anos, sexo feminino, Ia série, do lar)

Os alunos relataram ainda que seus professores são bons embora apontem para a atitude rigorosa de alguns deles. Eles falam das características ruins, quando se referem aos antigos professores, aqueles da infância ou de alguns professores de seus filhos e netos.

"Ensina bem. Ela explica bem. Fala o parágrafo, letra maiúscula, respeita vírgula, gosta que separa corretamente as letra. $O$ pessoal comentou que ela é brava, mas eu não tô achando não. Acho que ela explica maravilhosamente bem". (M.F.B.C., 4I anos, sexo feminino, $4^{\mathrm{a}}$. série, do lar)

"Ela é uma ótima professora, ensina muito bem. Pra gente aprendê, vai dependê muito do aluno. A professora pediu pra não falá mal dela”. (F.C.A.G., $2 \mathrm{I}$ anos, sexo masculino, $\mathrm{I}^{\mathrm{a}}$. série, desempregado)

Com relação às atividades trabalhadas em sala de aula, as que eles mais gostam são as de língua portuguesa e as que menos gostam as de matemática. As contas de adição e subtração são as que eles mais gostam e as de multiplicação as que não gostam tanto. Muitos alunos não se sentem capazes de realizar algumas tarefas e camuflam essa incapacidade ou pseudo-incapacidade, dizendo que não gostam. Suas opiniões podem ser identificadas em algumas falas:

"Que eu gosto mais é de escrevê. Gosto muito de lê, porque quanto mais a gente lê, mais a gente aprende". (T.M.S.S., 68 anos, sexo feminino, $4^{\mathrm{a}}$. série, do lar)

"Continha, das mais simples. Juntar as sílabas para forma palavras". (J.T.A., 45 anos, sexo feminino, $2^{\mathrm{a}}$. série, do lar) 
"Não gosto de texto - leitura e interpretação, não vô ca cara disso". (M.F.O.G., 39 anos, sexo feminino , $2^{a}$. série, do lar)

"Aquela história cumprida que tem que lê, porque tem a redação, a gente tem que escrevê, é difícil". (M.S.M.B., 53 anos, sexo feminino, $3^{a}$. série, do lar)

Outros estudantes afirmaram ainda que se estão na escola é para aprender de tudo e que não adianta querer aprender algumas coisas e outras não e que precisam gostar de tudo:

"Completá as frase, quando tem o espaço. A conta, tem umas que é fácil, mas tem outra que é difícil. $\mathrm{Na}$ sala de aula, tem coisa que a gente tem que fazê, mas não é tudo que a gente gosta". (R.P.O., 56 anos, sexo feminino, $4^{a}$. série, do lar)

"Nenhuma atividade, pois estou aprendendo e não posso criticar a professora". (R.L.F., 36 anos, sexo masculino, $I^{a}$. série, comerciante)

Destaca-se ainda que as disciplinas, português e matemática, foram as mais elencadas e que as outras disciplinas são citadas, mas numa freqüência bem menor, podendo estar relacionado ao fato de que as necessidades imediatas apontadas pelos alunos de aquisição das habilidades de ler, escrever e calcular, também sejam as mais trabalhadas nas salas de aula em detrimento de outras disciplinas. Por outro lado, também pode ser evidente que esta população tem a expectativa de que a apropriação desse conhecimento básico lhes proporcionará melhores condições de inserção na vida social, expectativa esta também revelada pelos participantes do estudo de Souza (1994). Estudos como o de Santana (1996), Fátima (1997), Tavares (1999) e Almeida (2003) também identificaram a importância atribuída por este público à aprendizagem da leitura, escrita e cálculos matemáticos, embora, como apontado no estudo de Tavares (1999), os alunos tenham consciência de suas limitações no acesso dessas habilidades.

\section{Considerações Finais}

Inúmeras são as dificuldades de investigação com esta população, embora não menos importante do que as outras. Um dos caminhos para se iniciar o processo de mudança, no que diz respeito ao acesso e permanência de Jovens e Adultos na escola, é investigar falhas e sucessos na Educação dos mesmos e um dos caminhos possíveis é permitir que os alunos possam apontar seus anseios e dificuldades. Existe mesmo uma tendência atual em se priorizar, nas investigações, o estudo das percepções dos indivíduos, tendo em vista que esta seria a maneira mais direta de se conseguir informações sobre sentimentos, valores e expectativas dos mesmos.

Este estudo evidenciou aspectos da relação dos participantes da pesquisa e o seu processo de ensinoaprendizagem, podendo ser utilizados como ferramentas pelos professores que trabalham com essa modalidade de ensino. Como afirma Scocuglia (200I), a construção da consciência histórica e política do professor deveria ser preocupação constante dos cursos de formação de professores ou de formação continuada destinada aos mesmos e, acredita-se que esta formação passe pelo acesso e pela divulgação dos estudos da área. Espera-se que este estudo possa contribuir para o avanço dessas discussões.

\section{Referências}

Abreu, D.M.B. (1999). O conhecimento numérico de jovens e adultos alfabetizadores na (re)criação do conceito de número. Dissertação de Mestrado, Universidade Estadual de Campinas, Campinas-SP.

Almeida, M.L.S. (2003). Sujeitos não-alfabetizados: sujeitos de direitos, necessidades e desejos. Em L. Soares (Org.), Aprendendo com a diferença: estudos e pesquisas em educação de jovens e adultos (pp. 39-63). Belo Horizonte, Autêntica.

Alvarino, J.V. (2003). O processo de alfabetização de jovens e adultos nos assentamentos da reforma agrária na região extremo-norte/ES: 1999-2000. Dissertação de Mestrado, Universidade de Brasília, Brasília-DF. 
Amaral, W.R. (2003). A política de educação de jovens e adultos desenvolvida pela APEART no Paraná: Recontando sua história e seus princípios, seus passos e (des)compassos. Dissertação de Mestrado, Universidade Estadual Paulista, Marília-SP.

Anunciação, M.C.L. (1987). Telecurso de $1^{\circ}$. Grau em Pernambuco: Um estudo avaliativo. Dissertação de Mestrado, Universidade Metodista de Piracicaba, Piracicaba-SP.

Araújo, D.L. (1995). A construção da intertextualidade na produção textual de alfabetizados e adultos. Dissertação de Mestrado, Universidade Estadual de Campinas, Campinas-SP.

Araújo, M.S. (1990). Estudo do valor preditivo do conhecimento de categorização de sons na aprendizagem da leitura e a escrita em adultos. Dissertação de Mestrado Universidade Federal de Pernambuco, Recife-PE.

Asmar, L.T. (1990). Níveis de escrita do adulto analfabeto. Dissertação de Mestrado, Universidade Federal do Rio Grande do Sul, Porto Alegre-RS.

Bardin, L. (1977). Análise de conteúdo. Lisboa: Edições 70.

Bezerra Neto, L. (1998). Sem terra aprende e ensina: Um estudo sobre as práticas educativas e formativas do Movimento dos Trabalhadores Rurais sem Terra - MST - 1997-1998. Dissertação de Mestrado, Universidade Estadual de Campinas, Campinas-SP.

Braga, A.J.P. (1996). Do mobral ao computador: A implantação de um projeto de informática educativa na educação de jovens e adultos. Dissertação de Mestrado, Universidade Estadual de Campinas, Campinas-SP.

Burgos, C.M.C. (1990). Os camponeses também temos a palavra: Contradições e potencialidades em uma experiência de comunicação educativa rural. Dissertação de Mestrado, Universidade Estadual de Campinas, Campinas-SP.

Campos, S. (1998). O trabalho docente na educação de jovens e adultos trabalhadores. Dissertação de Mestrado, Universidade Estadual de Campinas, Campinas-SP.

Carvalho, M.M.G. (1998). Alfabetização-cidadão: Uma concepção de educação popular, na realização do Projeto MOVA/SP - 1989-1992. Dissertação de Mestrado, Pontifícia Universidade Católica de São Paulo, São PauloSP.

Casério, V.M.R. (2003). Educação de Jovens e Adultos: Pontos e contrapontos. Bauru: EDUSC.
Cordenonssi, A.M. (1998). Telecurso 2000: Educação para o trabalho. Dissertação de Mestrado, Universidade Metodista de Piracicaba, Piracicaba-SP.

Cossentini, A.A. (2002). A coesão na produção textual: Um estudo sobre textos produzidos por alunos da educação de jovens $\mathrm{e}$ adultos. Dissertação de Mestrado, Universidade Estadual Paulista, Assis-SP.

Costa, A.R.P. (1987). "A vez é nossa" uma tele-visão de como alfabetizar adultos. Dissertação de Mestrado, Universidade Federal de Pernambuco, Recife-PE.

Cruz, M.W. (1993). Processo de alfabetização de adultos: Sentimentos vividos nesta trajetória. Dissertação de Mestrado, Pontifícia Universidade Católica do Rio Grande do Sul, Porto Alegre-RS.

Danyluk, O. (200I). O adulto não escolarizado e o registro da linguagem matemática. Em O. Danyluk (Org.), Educação de adultos: Ampliando horizontes de conhecimento (pp. 17 44). Porto Alegre, Sulina.

Fantinato, M.C.C.B. (2003). Identidade e sobrevivência no Morro de São Carlos: Representações quantitativas e espaciais entre jovens e adultos. Tese de Doutorado, Universidade de São Paulo, São Paulo-SP.

Fátima, E.M. (1997). Expectativas sócio-educacionais de um grupo de alfabetizandos jovens e adultos no Distrito Federal, Dissertação de Mestrado, Universidade Católica de Brasília, Brasília-DF.

Fernandes, D.G. (2004). Alfabetização de jovens e adultos: Pontos críticos e desafios ( $2^{\mathrm{a}}$ ed.). Porto Alegre: Mediação.

Ferreira, A.C. (1998). O desafio de ensinar-aprender matemática no noturno: Um estudo das crenças de estudantes de uma escola pública de Belo Horizonte. Dissertação de Mestrado, Universidade Estadual de Campinas, Campinas-SP.

Foltran, N.S. (1993). Voltando aos bancos escolares: Um estudo da questão com os alunos do grupo de alfabetização de adultos do Balneário de Camboriú. Dissertação de Mestrado, Pontifícia Universidade Católica de São Paulo, São Paulo-SP.

Gakya, S \& Martinelli, S.C. (2005). Avaliação do reconhecimento de palavras em jovens e adultos. Psic, $6(I), 5 I-58$.

Gervásio, O.M. (1995). Aspectos fonológicos da variedade lingüística alfabetizando adulto. Dissertação de Mestrado, Universidade Federal de Goiás, Goiânia-GO. 
Instituto Brasileiro de Geografia e Estatística (2006). Estatísticas do século XX. Rio de Janeiro: IBGE.

Instituto Nacional de Estudos e Pesquisas Educacionais Anísio Teixeira / Ministério da Educação (2004). sinopse estatística da educação básica: Censo escolar 2004. Brasília: INEP / MEC.

José, E.A. \& Coelho, M.T. (1999). Problemas de aprendizagem. São Paulo: Ática.

Luiz, M.O.R. (2003) A memória operacional e aquisição de leitura em analfabetos adultos. Dissertação de Mestrado, Universidade de São Paulo, São Paulo-SP.

Machado, M.M. (1997). Política educacional para jovens e adultos: A experiência do Projeto AJA (1993-1996). Dissertação de Mestrado, Universidade Federal de Goiás, Goiânia-GO.

Manfredi, S.M. (1976). Uma interpretação sociológica do programa nacional de alfabetização instituído pelo decreto n. 53.465 de I I/0I//964 e revogado pelo decreto n. 53.886 de 14/04/1964. Dissertação de Mestrado, Universidade de São Paulo, São Paulo-SP.

Marques, M.A.S. (1977). Aprovação e reprovação nas classes de alfabetização funcional no Mobral: Um estudo de caso em Salvador. Dissertação de Mestrado, Universidade de São Paulo, São Paulo-SP.

Moll, J. (1998). Redes sociais e processos educativos: Um estudo dos nexos da educação de adultos com o movimento comunitário e as práticas escolares no Morro Alegre (POA). Tese de Doutorado, Universidade Federal do Rio Grande do Sul, Porto Alegre-RS.

Monteiro, A. (1998). Étnomatemática: as possibilidades pedagógicias num curso de alfabetização para trabalhadores rurais assentados. Tese de Doutorado, Universidade Estadual de Campinas, Campinas-SP.

Montero, M.L. (1996). Comportamento do professor e resultados da aprendizagem: análise de algumas relações. Em C. Coll, J. Palácios \& A. Marchesi, Desenvolvimento psicológico e educação: Psicologia da educação (pp. 222243). Porto Alegre: Artes Médicas Sul.

Moraes, Z.R. (1994). Influência da alfabetização e da escolarização no desenvolvimento cognitivo e lingüístico. Dissertação de Mestrado, Universidade Federal de Santa Maria, Santa Maria-RS.

Nepomuceno, L.A. (1990). A influência da alfabetização nas capacidades metafonológicas em adultos. Dissertação de
Mestrado, Universidade Federal de São Paulo, São PauloSP.

Neptune, J.B. (1989). CEPEC: A escola cidadã. Dissertação de Mestrado, Universidade Estadual de Campinas, Campinas-SP.

Nogueira, M.M.N. (1995). A elaboração do texto no processo de alfabetização. Dissertação de Mestrado, Universidade Federal de Santa Maria, Santa Maria-RS.

Oliveira, J.M.S. (1997). Suplência: (Re)construindo a educação de jovens e adultos. Dissertação de Mestrado, Universidade Federal da Bahia, Salvador-BA.

Oliveira, M.C. (1996). Metaformose na construção do alfabetizandopessoa. Dissertação de Mestrado, Pontifícia Universidade Católica do Rio Grande do Sul, Porto Alegre-RS.

Piconez, S.C.B. (1995). Educação escolar de adultos: Possibilidades de reconstrução de conhecimentos no desenvolvimento do trabalho pedagógico e suas implicações na formação de professores. Tese de Doutorado, Universidade de São Paulo, São Paulo-SP.

Pierro, M.C.D. (1996). Políticas municipais de educação básica de jovens e adultos no Brasil: Um estudo do caso de Porto Alegre/RS. Dissertação de Mestrado, Pontifícia Universidade Católica de São Paulo, São Paulo-SP.

Pravadelli, C. (1997). Educação a distância: pesquisa realizada em empresas que implantaram o Telecurso 2000. Dissertação de Mestrado, Universidade de São Paulo, São Paulo-SP.

Richardson, R.J.; Peres, J.A.S.; Correia, L.M.; Peres, M.H.M.; Wanderley, J.C.V. (1989). Pesquisa social: Métodos e técnicas. São Paulo: Atlas.

Sachetti, V.A.R. (1992). A arte de ensinar: Um estudo das expectativas e concepções de alunos adultos analfabetos sobre o desempenho do professor. Dissertação de Mestrado, Pontifícia Universidade Católica de São Paulo, São PauloSP.

Santana, L. (1996). Usos e funções da leitura e da escrita para analfabetos e recém-alfabetizados. Dissertação de Mestrado, Universidade Federal de Minas Gerais, Belo Horizonte-MG.

Santos, G.L. (2003). Quando adultos voltam para a escola: o delicado equilíbrio para obter êxito na tentativa de elevação da escolaridade. Em L. Soares (Org.), Aprendendo com a diferença: estudos e pesquisas em educação de jovens e adultos (pp. I I-38). Belo Horizonte, Autêntica. 
Santos, S.R. (1992b). Alfabetização de adultos numa perspectiva epistemológica. Dissertação de Mestrado, Universidade Federal da Bahia, Salvador-BA.

Saraiva, M.I.M. (1998). Histórias de vida e outras história: Narração e memória na alfabetização de adultos. Dissertação de Mestrado, Universidade Federal Fluminense, Rio de Janeiro-RJ.

Sauner, N.F.M. (1994). Alfabetização de adultos: A interpretação de textos acompanhados de imagem. Tese de Doutorado, Universidade de São Paulo, São Paulo-SP.

Scocuglia, A.C. (200I). Histórias inéditas da educação popular: Do sistema Paulo Freire aos IPMS da ditadura. São Paulo: Cortez \& Instituto Paulo Freire.

Scomazzon, R.L.G. (199I). Educação de jovens e adultos trabalhadores: Análise de uma proposta educativa no cotidiano de professores e alunos. Dissertação de Mestrado, Universidade Federal do Rio Grande do Sul, Porto AlegreRS.

Silva, C.C.R.A. (1998). Explorando novos caminhos para a democracia: Os desafios da participação popular na gestão pública e o movimento de alfabetização de jovens e adultos da cidade de São Paulo (MOVA/SP, 1989-1992). Dissertação de Mestrado, Universidade Estadual de Campinas, Campinas-SP.

Silva, C.M.B.A. (1995). Ensino supletivo no Tocantins: Projeto Palmas - intenção X realidade. Dissertação de Mestrado, Universidade de Brasília, Brasília-DF.

Simões, C.G.G. (1995). Leitores e escritores em construção: Análise de uma prática junto a adultos pós-alfabetizandos. Dissertação de Mestrado, Universidade Federal de São Carlos, São Carlos-SP.

Slomp, P.F. (199I). Contextualização da leitura e escrita por adultos não-alfabetizados. Dissertação de Mestrado, Universidade Federal do Rio Grande do Sul, Porto Alegre-RS.
Soares, L.J.G. (1987). Do trabalho para a escola: As contradições a partir de uma experiência de escolarização de adultos. Dissertação de Mestrado, Universidade Federal de Minas Gerais, Belo Horizonte-MG.

Souza, A.B. (1994). A escola representada por alunos de cursos de alfabetização e pós-alfabetização de jovens e adultos que passaram anteriormente pelo ensino regular: Contribuição à compreensão do cotidiano escolar. Dissertação de Mestrado, Pontifícia Universidade Católica de São PauloSP.

Souza, A.L.S. (1996). Escrita e ação educativa: Uma visão de um grupo de alfabetizadores do MOVA-SP. Dissertação de Mestrado, Pontifícia Universidade Católica de São Paulo, São Paulo-SP.

Souza, A.M.C. (1988). Educação matemática na alfabetização de adultos e adolescentes segundo a proposta pedagógica de Paulo Freire. Dissertação de Mestrado, Universidade Federal do Espírito Santo, Vitória-ES.

Souza, R.F. (1991). Classes populares e educação popular na Primeira República: Problemas, valores e lutas. Dissertação de Mestrado, Universidade Estadual de Campinas, Campinas-SP.

Tavares, A.C.R. (1999). As leituras do mundo e as leituras das palavras: buscando significados na escolarização de jovens e adultos. Dissertação de Mestrado, Universidade Federal do Rio Grande do Sul, Porto Alegre, RS.

Toledo, M.E.R.O. (1998). As construções matemáticas dos alunos adultos pouco escolarizados: Das resoluções cotidianas ao registro formal. Dissertação de Mestrado, Universidade de São Paulo, São Paulo-SP.

Recebido em: 21/02/2006

Revisado em: 16/08/2006

Aprovado em: 30/1 I/2006

Sobre as autoras

Poliana da Silva Almeida Santos Camargo (santcam@uol.com.br) é mestre em Educação pela UNICAMP, Docente da Universidade do Sagrado Coração, Diretora e Coordenadora Pedagógica do Colégio “La Salle” - Bauru/SP.

Selma de Cássia Martinelli (selmacm@unicamp.br) é professora doutora do Departamento de Psicologia Educacional da Universidade Estadual de Campinas - UNICAMP, Campinas / SP.

Endereço para correspondência

Selma de Cássia Martinelli

Rua Bertrand Russell, 80I.Faculdade de Educação

Cidade Universitária- Distrito Barão Geraldo

|308|-970 - Campinas, SP 